Dear Author,

Please, note that changes made to the HTML content will be added to the article before publication, but are not reflected in this PDF.

Note also that this file should not be used for submitting corrections. 


\title{
Evaluation of the GPR frequency spectra in asphalt pavement assessment
}

\author{
J. Pedret Rodés ${ }^{\mathrm{a}, *}$, V. Pérez-Gracia ${ }^{\mathrm{b}}$, A. Martínez-Reguero $^{\mathrm{a}}$ \\ ${ }^{a}$ Dpt. of Transport and Regional Planning, Universitat Politècnica de Catalunya-BarcelonaTech, C/Jordi Girona 1-3, 08034 Barcelona, Spain \\ ${ }^{\mathrm{b}}$ Dpt. of Strength of Materials and Structural Engineering, EUETIB/CEIB, Universitat Politècnica de Catalunya-BarcelonaTech, C/Urgell 187, 08036 Barcelona, Spain
}

\section{H I G H L I G H T S}

- This paper discusses the use of frequency analysis in GPR assessment of pavements.

- A section of a highway was studied in two different stages of its service life.

- Changes in frequencies are associated to changes of the layers thicknesses and moisture.

- The spectrum shows divisions that could be in this case associated to different layers.

\section{A R T I C L E I N F O}

\section{Article history:}

Received 30 March 2015

Received in revised form 21 July 2015

Accepted 5 August 2015

Available online $\mathrm{xxxx}$

\section{Keywords:}

Ground penetrating radar

Pavement assessment

Frequency analysis

\begin{abstract}
A B S T R A C T
Ground penetrating radar (GPR) is frequently used in pavement assessments, mainly using the evaluation of wave travel times. However, GPR data provide further information that could be used in order to determine the inner conditions and characteristics about materials. In this paper, the possible analysis of the frequency spectrum of GPR signals is analysed and discussed. Several tests were carried out in a portion of a highway in two different stages of its service life. Results highlight the relationship between the shape of the spectrum and the frequency signature with the structure and conditions of the pavement.
\end{abstract} (c) 2015 Published by Elsevier Ltd.

\section{Introduction}

\subsection{Rational flexible pavement rehabilitation according to the AASHTO} guide

The AASHTO pavement rehabilitation guide [1] regulates the design of reinforcement in flexible pavements based on the stress and strain calculation model in a Burmister multi-layer system [2]. The method is based on determining the stiffness modulus of each layer that makes up the pavement using back-calculation in order to obtain the state of stress and strain in significant points [3].

This model considers two decisive values: (1) the maximum permissible horizontal tensile strain at the bottom of the deepest bituminous layer, and (2) the maximum allowable vertical compressive strain at the top of the subgrade. The more critical of the two values is used to define the service life of the complete structure.

* Corresponding author.

E-mail addresses: josep.pedret@upc.edu (J. Pedret Rodés), vega.perez@upc.edu (V. Pérez-Gracia), Adriana.martinez@upc.edu (A. Martínez-Reguero).
This method requires, as input data, the deflection obtained under the application of a standardised load and the thicknesses of each one of the layers of the pavement. The use of Falling Weight Deflectometer (FWD) and Ground-Penetrating Radar (GPR) are recommended to obtain these data. Accordingly, the combined results of both methods are used to define the stiffness of the pavement due to they provide quantitative parameters related to rigidity. However, the two methods are affected by the uncertainty associated with all indirect methodologies. Moreover, external variables as temperature and moisture, could influence on the results of the measurements. This work presents some preliminary tests based on analyzing radar frequencies, discussing the possible effect of moisture, changes in the layers thickness and porosity on the radar signals, in order to diminish the uncertainty in the results and to explore the ability of the method to detect changes in pavement layers.

\subsection{Advances in the use of GPR in pavement rehabilitation}

The application of GPR technology in civil engineering topics started in the 1970s decade, after the development of the first commercial equipment for civil use [4]. In just a few years, subsoil 
prospecting equipments were available on the market with many uses, including for pavements assessment. Some years later, the first works on the use of the GPR in pavement evaluations were published with the aim of determining pavement thicknesses and locating cavities beneath the structure of a road (e.g., [5-8]).

In 1987, the American Society for Testing and Materials published the first recommendations for use of GPR for measuring pavement layers [9]. This document has been revised on two occasions, 1998 [10] and 2010 [11]. During this period, the first monograph was also published referring to the use of GPR as a support tool for preventive maintenance of asphalt pavements [12].

The works of Eckrose in 1989 [13] and Briggs et al. in 1991 [14] established the bases for finding both the thickness and the conditions of a pavement at the same time with the objective of approaching the design of reinforcement using the backcalculation method.

Somewhat later, in 1996, Maser [15] analysed the type of antennas in asphalt pavements studies, and Saarenketo in 1997 [16] obtained an approach to the density of the materials using the dielectric constant. In this period, other authors also studied the dielectric properties of different types of pavement, such as concrete [17]. In 1998, Morey published a complete work concerning the use of GPR in transport infrastructures [18]. Subsequently, Saarenketo and Scullion [19] proposed the dielectric constant as a variable obtained using the GPR test for detecting cracks in pavements, and they compared that constant with the results obtained by using FWD.

In 2002, the AASHTO guide [1] included, for the first time, GPR tests for measuring road surface thicknesses and identifying failure pathologies in the structure. The results from those tests allowed dividing the road in different homogenous segments, depending on the GPR data results. Hence, the results of the backcalculation were adjusted for each different segment, improving the interpretation of the deflection bowls. In 2004, AASHTO also published the first version of its official GPR usage and recommendations manual. This document is known as AASHTO R-37 [20].

The most recent publications on the use of GPR on pavements are mainly focussed on identifying indirect variables associated with their inner conditions. Some of these publications have been devoted to the tests of sensitivity, considering various external factors that may affect the measured variables. For example, [21] analyses the climatic factors that may affect the measurement of the layer thicknesses [22]; studies the uncertainty in the calculation of the density of the layers due to the presence of water [23]; analyses the external factors that may have an impact on the correct identification of debonded areas between layers; [24] analyses density and moisture in discontinuities based on the reflected wave amplitude in radar images, detecting zones poorly compacted, and comparing GPR data to X-ray imaging. More recent intensive applications demonstrate the potential of the methodology in the assessment of many parameters that affect the pavements: compaction uniformity, thicknesses, zones with water retention and low density areas [25].

In 2011, Leng [26] compiles various pavement analysis techniques such as the detection of wave front scattering, obtaining the relative dielectric permittivity (or of the wave propagation velocity) by means of the Common Midpoint (CMP) method.

\subsection{The frequency spectrum of the GPR signals}

The radio-electric emission spectrum of a GPR antenna represents the frequency distribution of the electromagnetic energy emitted by that antenna in one pulse. The spectrum can be found applying the Fourier transform to the A-scans. The Fourier transform decomposes the function of time into the frequencies, allowing to define different contributions of each one of the frequencies of the recorded signal. Extensive description of this process can be found in many references, for example in [27].

GPR antennas emit ultra-wide band microwave or radiofrequency pulses. During the propagation of the signal through the media, the frequency signature changes as the media acts as a low-pass filter [28]. To determine to what extent this phenomenon is occurring, the frequency signature of the received waves must be analysed by comparing it with the spectrum of the emitted signal and thus observing the frequency ranges absorbed or attenuated by the materials of the medium.

Usually, the frequency signature of a GPR signal is analysed by determining the central spectrum frequency and its bandwidth. Other methods are based on the analysis of the asymmetry of the received signal spectrum and of the distribution of the reflected and absorbed energy [29]. These studies demonstrate the significant relationship between the wave propagation velocity and the GPR signal frequency signature [30]. However, most of the pavement studies are based on the relationship between the wave propagation velocity and its dependency on the relative dielectric permittivity of the medium in order to evaluate possible deterioration [31], without analysing the frequencies of the received signals. Notwithstanding, some noteworthy studies are focused on the detection of moisture in construction materials. A remarkable result of some of those studies is the progressive reduction of the bandwidth and the shifting of the central frequency to lower values as the water content increases. These analysis were applied to concrete [32,33], to ballast for railway infrastructure [34,35] and to other media [36].

Other studies have analysed the alterations in the frequency spectra as the ratio of two materials changes. For example, it has been observed that as a larger proportion of clay is added to a sandy soil, the central frequency and the bandwidth of the signal reduces and the maximum amplitude of the reflected wave increases [37].

Analysis of the signal frequencies has also been used to locate mineral or hydrocarbon reserves [38], although at frequency ranges lower than those that are usual in pavement studies. Other studies were based on laboratory tests, showing the dependence of the frequency signature with water content [39]. Those results seem to indicate that the analysis of field data based on the characteristics of the frequency signature could be an interesting additional information in the pavement assessment.

\subsection{Purpose of study}

Based on those previous studies, this paper presents some first tests carried out to check the sensitivity of an electromagnetic wave in the frequency domain in the diagnostic assessment of asphalt pavement pathologies.

The analysis is focused on determining the changes in the spectrum by comparing the received signal frequency signature with the spectrum of the signal emitted by commercial GPR equipment. The changes that are observed in the analysis are related to different anomalies in the pavement materials, in many cases to the existence of cavities and moisture because the bearing capacity of a road pavement is highly affected by those parameters.

To achieve the main objectives, three different surveys were carried out. The first one was a GPR assessment of the road after its construction. The second one was a FDW survey. Based on these two previous analyses, certain segments of a highway pavement were selected. Subsequently, data was acquired with GPR and finally a selective asphalt core extraction was carried out to check the results. 


\section{Methodology}

\subsection{Type of pavement tested}

The tests were carried out on a $2.5 \mathrm{~km}$ length section of a highway that is one of the main access routes to the metropolitan area of Barcelona through the west of the city. This section is characterized by its flexible pavement which was constructed and open to service in 2004 and has a design life of 20 years. The pavement structure was built with thicker granular and asphalt layers.

The high thickness of the layers reduces the incidence of undesirable effects due to discontinuities and construction factors in the frequency spectrum of the signal.

The standard cross-section of the pavement is made up of distinct asphalt mix layers with a total design thickness of $30 \mathrm{~cm}$ over a $25 \mathrm{~cm}$ thick granular base, as shown in Fig. 1. In this well delimited section, FWD and GPR methods were applied in the study of the pavement, being FDW used to select the areas studied with GPR. Some results from both methodologies were also compared and commented.

\subsection{Data acquisition}

Two GPR surveys (both with a nominal $800 \mathrm{MHz}$ centre frequency antenna) were carried out on the same section of a highway in different periods. The spectrum of the signal emitted by the antenna used in the tests is shown in Fig. 2. The maximum amplitude peak appears at frequencies close to $850 \mathrm{MHz}$, and the centre frequency for $3 \mathrm{~dB}$ is about $950 \mathrm{MHz}$. The vertical resolution can be considered as the wavelength of the received signal divided by 4 . Since the average velocity is about $10 \mathrm{~cm} / \mathrm{ns}$ and the centre frequency is close $950 \mathrm{MHz}$, the theoretical expected resolution is about $3 \mathrm{~cm}$ in this particular study.

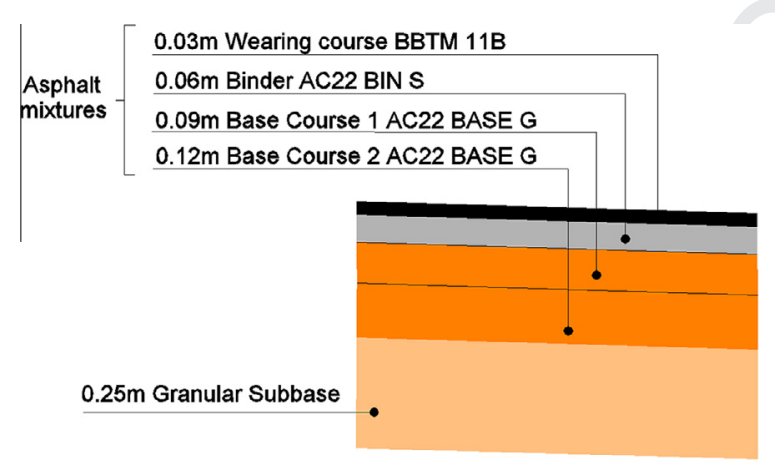

Fig. 1. Pavement cross section tested.

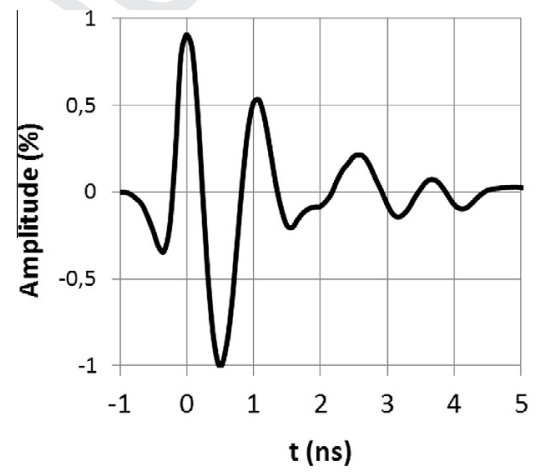

The first survey was in 2004, before the highway was open to traffic; the second, in 2013, after a FWD analysis. The previous deflection assessment with FWD, before the second GPR survey, was used to identify the most suitable sections for the tests, considering the objectives of the study. Each deflection value corresponds to a particular point, and is also corrected for temperature and humidity, in accordance with the equations of the Asphalt Institute [40]. The sectioning of results obeys the standard application calculation criteria of the accumulated finite differences in accordance with the 1993 version of the AASHTO pavement design guide $[41,42]$. The criterion for the selection of the zones for the further GPR assessments was the existence of important anomalies in the FDW results. In addition, a zone with regular and homogeneous FDW results was also selected in order to have reference values.

In the two GPR tests, a vehicle was used in order to move the antenna at a speed that prevented traffic being held up, and one sample was acquired every $25 \mathrm{~cm}$ using a sampling frequency of about $15 \mathrm{GHz}$.

The antenna was fitted to the rear of the tractor vehicle away from the noise of the engine and sufficiently separated from the body of the vehicle. The distance between the antenna and the pavement surface was about $15 \mathrm{~cm}$ (Fig. 3), preventing possible accidental impacts of the antenna with the ground during the radar data acquisition.

GPR and FWD results were checked with cores that were extracted in accordance with the study requirements.

\subsection{GPR signal processing}

Radar data was processed in three steps. Firstly, the sections of greatest interest were selected based on the preliminary GPR (measurements in the first stage) and FWD results. As consequence, the road was divided in zones characterized by their radar image and with similar properties. Secondly, every one of these sections was divided in zones of $5 \mathrm{~m}$ length showing approximately homogeneous images. In each one of those zones, the A-scans along $5 \mathrm{~m}$ were averaged, obtaining a mean value that was defined as distinctive of the zone. Thirdly, the mean A-scans in time domain were converted into spectra in the frequency domain.

Fig. 4 shows typical results obtained in a zone with standard structural cross-section and with no detected construction pathologies. The core (Fig. 4a) shows the pavement cross-section. The contacts between layers correspond to every one of the peaks that appears in the graph of Fig. $4 \mathrm{~b}$. This diagram represents the envelope of the trace amplitude, recorded in the time domain. However, as consequence of small heterogeneities, some particular scans could not represent the average characteristics of the studied zone. Therefore, in order to prevent the use of signals affected by

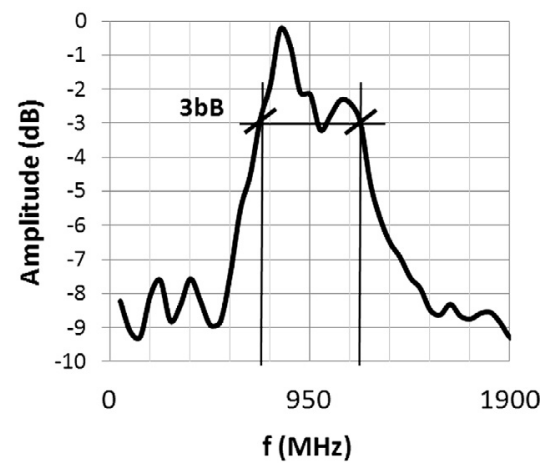

Fig. 2. GPR data in air obtained with the antenna used in the field tests, and the spectrum. 


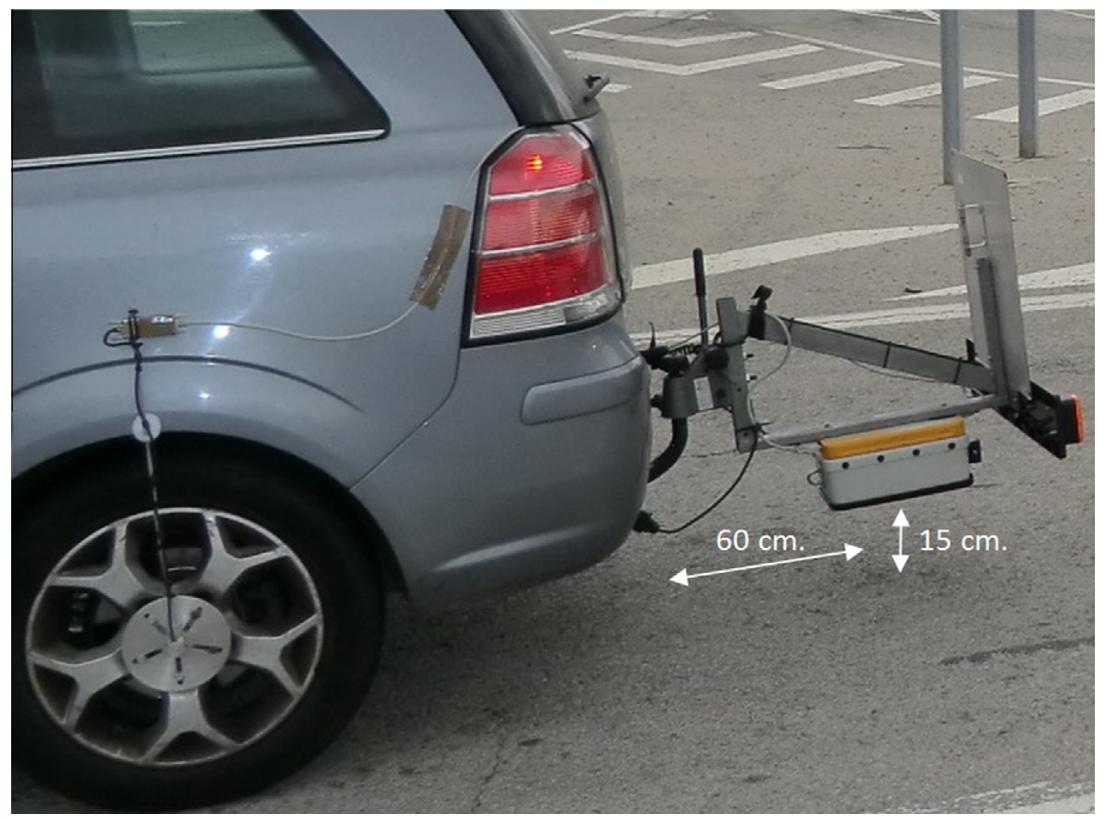

Fig. 3. GPR device used for testing.

(a)

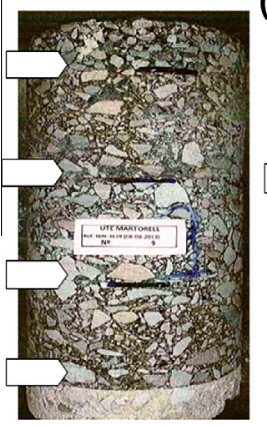

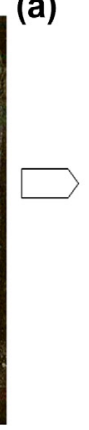

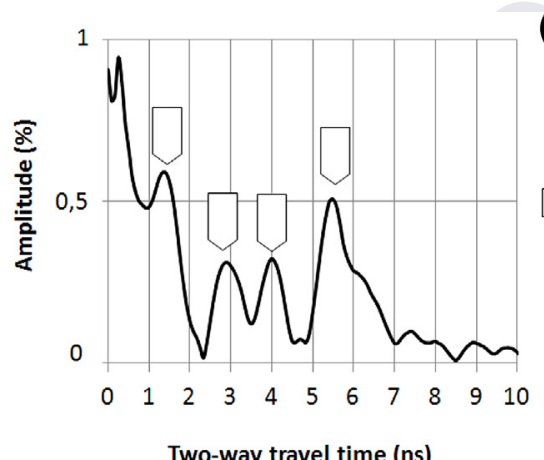

(b)

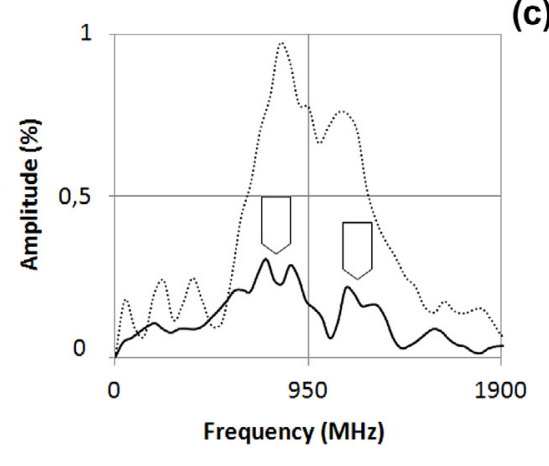

(c)

........... air spectrum _ pavement spectrum

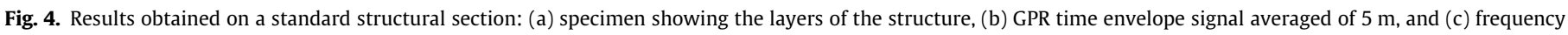
content, in average.

the existence of no representative targets, all the scans recorded in each selected section were averaged. Hence, the absolute value of the wave amplitudes shown in Fig. 4 represents the average of 20 scans. The spectrum was obtained with a Fourier transform of the time averaged signal (Fig. 4c).

The core in Fig. 4a denotes the existence of four asphalt layers that are perfectly adhered together but built with different mixes. The upper layer $(A)$ is the most different from the other layers due to its aggregate gradation, its void content and its aggregate nature, which is the granite type. The other three layers are made up of limestone aggregates and are differentiated from each other by their aggregate gradation and by the voids and bitumen content.

The peaks corresponding to the maximum amplitudes in Fig. $4 \mathrm{~b}$ are associated to each one of the transitions between layers and the number of peaks that represent them. The peak at a time of about $5.5 \mathrm{~ns}$ corresponds to the transition between the bottom bituminous layer and the granular base. The peaks at earlier times correspond to each one of the transitions between bituminous layers. The first peak at 0 ns corresponds to the transition between the air and the pavement surface.
Finally, the frequency distribution of the received signal is exhibited in Fig. 4c. The graph shows two main areas that can be associated with the existence of two media characterised by different electromagnetic properties: AC (Asphalt concrete) and GB (Granular Base).

These two main zones of the spectrum denote that most of the energy reflected is between $700 \mathrm{MHz}$ and $900 \mathrm{MHz}$, and between 1100 and $1300 \mathrm{MHz}$, presenting this second zone lower amplitudes.

\section{Results}

3.1. Effect of the layer thickness variations on the frequency signature

In order to check the sensitivity of the frequency signature to the thickness of the two different types of aggregates in a two-layer system, the spectrum obtained was analysed by varying the thickness ratio between the two layers. Therefore, a transition wedge embedded in the pavement was utilised with the objective 
of highlighting the possible effects as consequence of changes in thicknesses of the layers.

The transition wedge was a construction element used to facilitate the transition from flexible pavement to a concrete structure. It consisted of progressively increasing the thickness of the standard cross-section of the asphalt, $25 \mathrm{~m}$ before arriving at the concrete structure. Its purpose was to progressively increase the stiffness of the system in order to minimise the transition effects from a flexible and deformable structure to a non-deformable and rigid structure.

Fig. 5 shows the radar data (radargram) obtained over this transition wedge where the most noticeable anomaly is probably caused by the contact between the asphalt layers and the granular base. The two way travel time to this target is progressively increased as the thickness of the wedge increases. Four points (A, B, C and D in Fig. 5), separated by $5 \mathrm{~m}$, were used in this evaluation carried out during the first stage of the survey, prior to the putting into service of the infrastructure. Accordingly, the assessed zone was supposed homogeneous enough and without damage as consequence of use. Consequently, the values for the most important electromagnetic properties of the materials that make up layers AC and GB were obtained from the literature. One of the most frequently used guides was published by Russel in 2011 [43], which gives the values shown in Table 1 for air, bitumen, limestone and water. The materials that make up the asphalt layers and granular base were also considered to be those given by technical specifications of materials for new constructions [44] (see Table 2).

In Fig. 5, point A represents the standard cross-section thickness, and point $\mathrm{D}$ corresponds to the pavement thickness at the beginning of the concrete slab. The two-way travel time corresponding to four different points in the area (A, B, C and D) are shown in Table 3.

By considering the data in Tables 1 and 2, it could be considered that the dielectric permittivity of the AC might be smaller than the value corresponding to the GB layer, mainly because of the water content of the GB layer is higher. Furthermore, the spectrum in the case of high water content is usually characterized by lower frequencies [e.g., [39]]. Therefore, the range of frequencies corresponding to the AC layer should include higher frequency values than that corresponding to the GB layer. Fig. 6 shows the spectrum corresponding to the scans from each one of the representative points of the transition wedge A, B, C and D represented in Fig. 5, compared to the spectrum of a direct wave propagated by air. At the four points, the spectrum denotes that the frequency signature could be separated into two main zones. The first one (at lower frequencies) is characterised by a main peak of higher amplitude corresponding to a central frequency close to $800 \mathrm{MHz}$. The bandwidth around this $800 \mathrm{MHz}$ peak, measured at $3 \mathrm{~dB}$, is similar in the four points. Regarding that this area remains constant, it could be considered that those lower frequencies most likely
Table 1

Electromagnetic parameters for the different materials [40].

\begin{tabular}{lllll}
\hline & Air & Bitumen & Limestone & Water \\
\hline Relative dielectric permittivity $\left(\varepsilon_{\mathrm{r}}\right)$ & 1 & $3-5$ & $7-9$ & 81 \\
Wave velocity $(\mathrm{mm} / \mathrm{ns})$ & 300 & $134-173$ & $100-113$ & $30-35$
\end{tabular}

Table 2

Estimated composition of each layer according to Spanish specifications [41].

\begin{tabular}{lllll}
\hline & \multicolumn{4}{l}{ Average content $(\%)$} \\
\cline { 2 - 5 } & Voids & Bitumen & Limestone & Water \\
\hline AC layers & 5 & 5 & 90 & 2 \\
GB layers & 10 & 0 & 80 & 10 \\
\hline
\end{tabular}

Table 3

Location of the four measured points (A, B, C and D in Fig. 5) and depth to the contact AC-GB.

\begin{tabular}{lll}
\hline & Distance from the origin $(\mathrm{m})$ & AC thickness $(\mathrm{cm})$ \\
\hline Point A & 30 & 30 \\
Point B & 35 & 35 \\
Point C & 40 & 40 \\
Point D & 45 & 45 \\
\hline
\end{tabular}

corresponds to the signal reflected at the contact between the GB layer and the deeper layers, the characteristics of which remain invariable at the four analysed points.

Furthermore, a second zone of the spectrum can be seen within a range of frequencies higher than this $800 \mathrm{MHz}$ main peak. In this second zone, a secondary peak presents different amplitudes for each one of the four different points. The amplitude of this secondary peak increases as the thickness of the asphalt layers increases. Moreover, the bandwidth of this second area of the spectrum also increases as the layer thickness increases. This behaviour could associate this second part of the spectrum to the reflection in the contact between the AC and GB layers.

Besides, the frequency of the second main peak associated with the $\mathrm{AC}-\mathrm{GB}$ contact moves towards the low frequencies as the thickness of the material increases. This phenomenon could be explained by the higher presence of water in the semi-dense or course mixes commonly used as asphalt base mixes, which present about a $10 \%$ of water content.

\subsection{Effect of moisture on the frequency signature}

The water in the deepest layers of a pavement is one of the main causes of greater structural deterioration that significantly affects the bearing capacity of the road. These losses of stiffness can be greater than $50 \%$ depending on the season and weather during the deflection measurements [45].
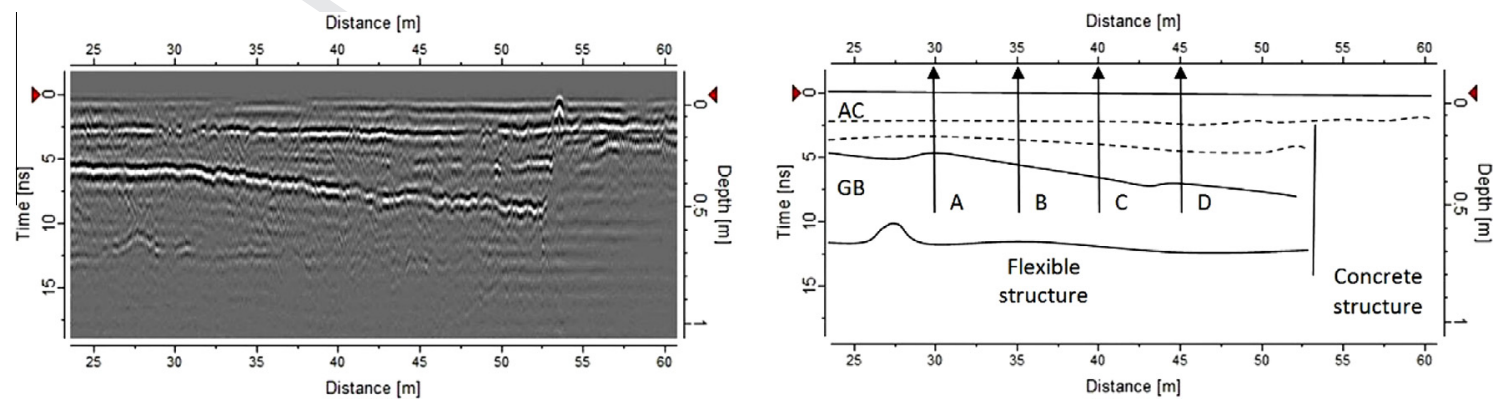

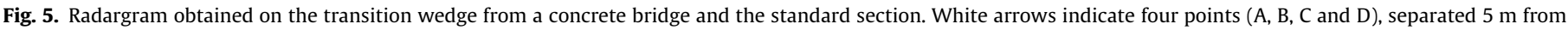
each other, superposed on the transition wedge. 

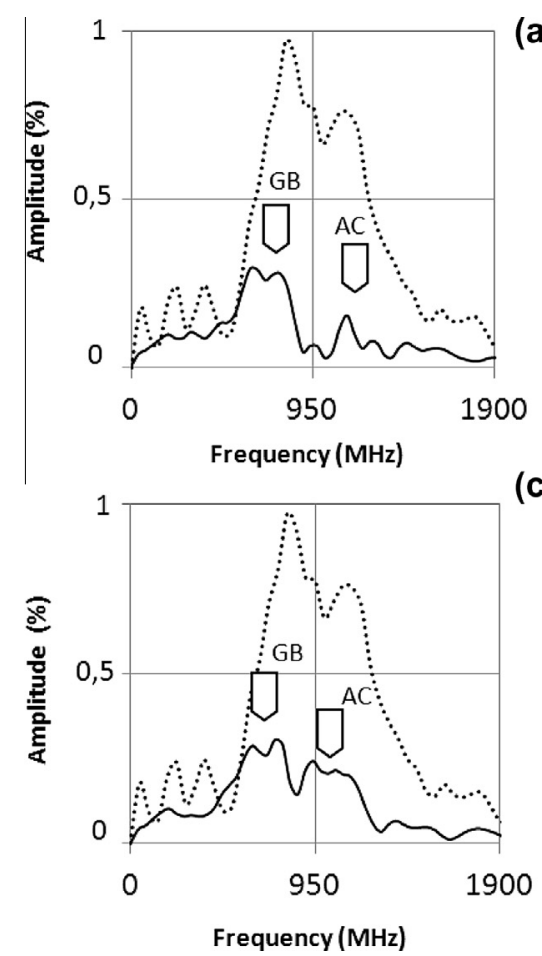

(a)

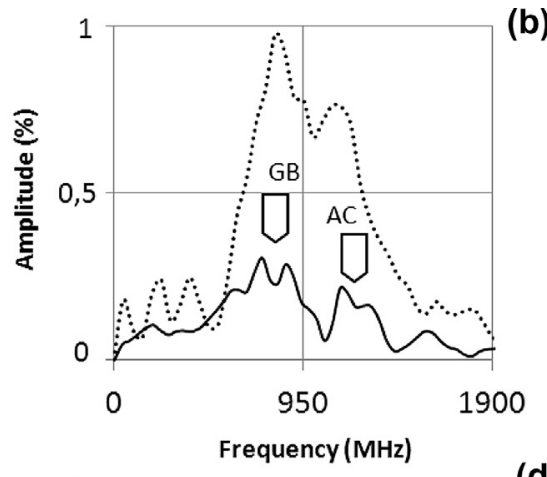

(c)

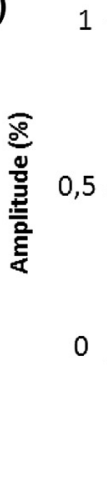

(b)

(d)

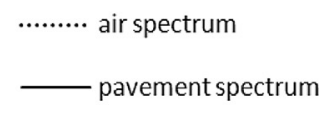

Fig. 6. Response spectra obtained in the measurement points A, B, C and D. The frequencies that could correspond to the GB and AC layers are marked with arrows.

A deflection bowl obtained in an area with materials that contains high percentage of water in their pores presented high deflection values in all the geophones, as well as a low resilience, observed in the sensors furthest from the load application point (Fig. 7b).

Moreover, asphalt cores from the section affected by moisture highlighted the deterioration. Fig. 7a shows an asphalt core extracted from an area affected by high water content. Besides, this asphalt core evidences the important loss of bonding between the AC and GB layers.

The frequency signature corresponding to the GPR record in this damaged area (Fig. 7c) underscored a significant reduction of the bandwidth in the section associated to the GB layer. Additionally, the maximum amplitude spectrum peaks were significantly moved towards the low frequencies. As consequence, the peak centred at approximately $800 \mathrm{MHz}$ in the case of the new pavement was moved to a frequency close to $700 \mathrm{MHz}$ in the data obtained in the deteriorated pavement. Furthermore, the peak associated with the contact between $\mathrm{AC}$ and $\mathrm{GB}$, around $1200 \mathrm{MHz}$ in the case of the new pavement, was close to $850 \mathrm{MHz}$ for the deteriorated pavement.

\subsection{Effect of air (porosity) on the frequency signature}

Another cause of failure of the pavement is the loss of bonding at the interface between layers, due to the deterioration or poor adhesion of the tack coat. The service life of the pavement exposed to cyclic load stresses can be reduced by around $50 \%$ when the bonding between layers is reduced about to $10 \%$ [46].

The deflection bowl obtained in an area with loss of bonding between layers showed high deflection values in the geophones closest to the load application points, and the sensors furthest away (Fig. 8b) exhibited a rapid recovery. Consequently, the debonding caused an overload in the lower layers that weakens them and progressively reduced their service life.

Fig. 8 shows the results of the tests carried out in an area with loss of bonding. The asphalt core extracted in this section (Fig. 8a) denotes the deterioration at the contact surfaces between the different AC layers.

The frequency spectrum (Fig. 8c) exhibits that the range of frequencies corresponding to the reflection on the GB contact remains invariable compared to the pavement in its original condition (obtained from the first stage of measurements).
409

\section{(a)}
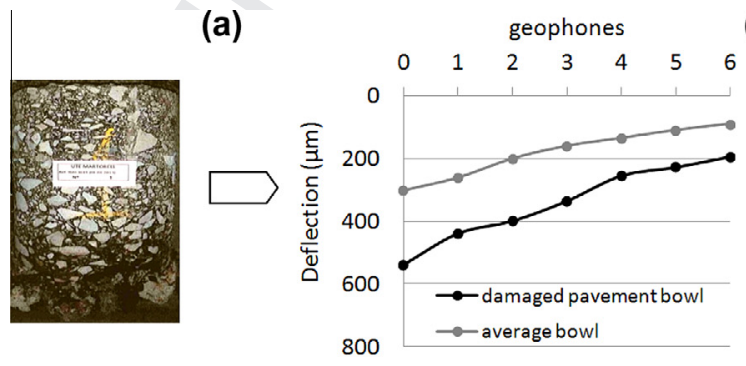

(b)

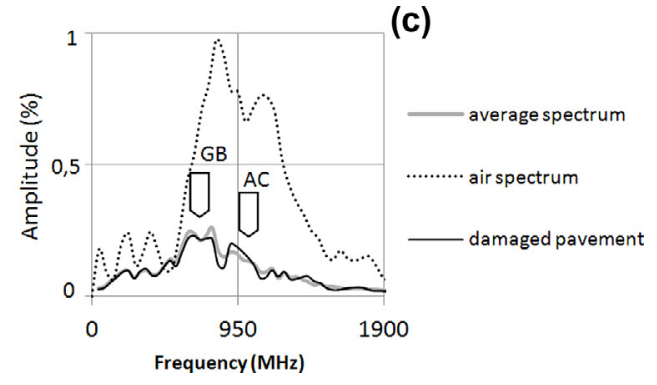

Fig. 7. (a) core, (b) deflections and (c) GPR spectrum signal, from a pavement section where moisture problems in the sub grade are known. 

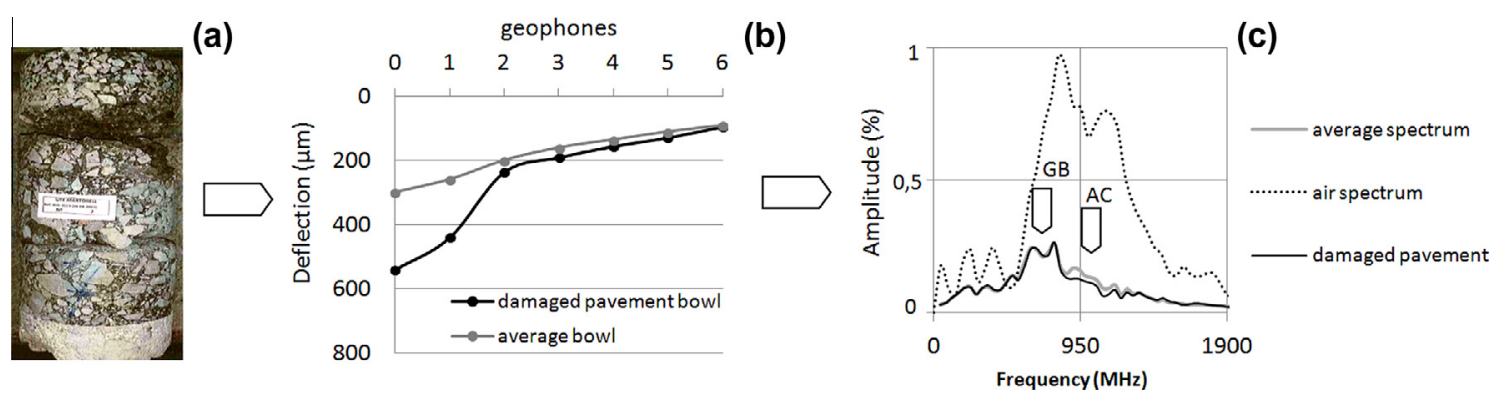

Fig. 8. (a) core, (b) deflections and (c) GPR spectrum signal, from a pavement section where the cohesion between layers of asphalt mixture problems is known.

Notwithstanding, the range of frequencies corresponding to the AC layer is characterized by 3 high amplitude peaks at frequencies between $900 \mathrm{MHz}$ and $1300 \mathrm{MHz}$. This splitting of the bandwidth could be caused by the layer debonding (Fig. 8a).

\section{Conclusions}

This work was devoted to determine the differences on the frequency signature of GPR signals obtained in the pavement assessment, depending on the characteristics and conditions of the pavement layers. The results obtained after several measurements are described in this paper, being the possible base to further analysis. Although GPR survey is commonly used in the assessment of roads, the applications used to be focused on the wave velocity and on the wave amplitude. Few studies has been devoted to the evaluation of the frequency signature as complementary data. The preliminary tests carried out in field reveal that this frequency analysis could be a helpful tool, although more studies and further statistical analysis might be carried out based on those first results presented in this paper.

The methodology consisted of the measurements on the main road in two different stages of its service life. The first survey was carried out just before the use of the road. The second survey was carried out four years later. Hence, radar data obtained in the first survey was assumed to be corresponding to perfect materials, without important damage, while the second survey provides data that was acquired in different zones characterized by different distresses and conservation actions. Therefore, the results were obtained to evaluate different characteristics, being those obtained in the second survey used to assess damage zones, highlighting the changes on the frequency that seem to be dependent on the damage. The main features deduced by this study indicate:

1. Changes in the frequency signature of the recorded signal are associated to changes on the layers thicknesses. The pavement materials act as a low pass filter, and the peaks of the spectrum are moved to lower frequencies in the case of layers with higher thicknesses. Moreover, the amplitude of the spectrum is reduced while the layer thickness is increased.

2. The existence of more than one layer could be associated to changes on the spectrum showing clearly two or more zones, each one most likely corresponding to the reflected energy in each one of the discontinuities. The analysis of a zone with an intermediate layer characterized by variable thickness emphasized the existence of areas of the spectrum without changes in all the zone, while in other zones the amplitude diminishes while the depth to the contact increases and the intermediate layer thickness decreases. Therefore, the analysis suggests that different zones of the spectrum could be associated to the reflections on different contacts.
3. Changes in water content seem to be associated to changes in the bandwidth of the spectrum that diminish while the water content increases. Additionally, higher moisture could correspond to a displacement of the spectrum peaks toward lower frequencies.

4. The increase of the porosity in the pavement layers causes an increase of the air content in the materials. The analysis of the spectrum of the GPR signals from different zones characterized by different porosities seems to indicate that the number of peaks of the spectrum increases as debonding between layers increases.

Finally, this study suggests the possibility of developing algorithms in order to segment roads depending on the frequency spectrum of GPR signals as an additional tool in pavement evaluation, based on the changes of the bandwidth and the maximum amplitude peaks along the same road.

\section{Acknowledgments}

The authors acknowledge the contribution of all persons and institutions that facilitate the radar acquisition tasks and the different experimental tests. The contribution of the Ministerio de Fomento of the Spanish Government was remarkably significant to the development of the work. This work has been also developed partially though a Spanish Government research project CGL2011-23621 funded partially by the European Commission with FEDER funds. The study is also a contribution to the EU-funded COST Action TU1208, "Civil Engineering Applications of Ground Penetrating Radar".

\section{References}

[1] National Cooperative Highway Research Program 1-37A: Guide for Mechanistic-Empirical Design of New and Rehabilitated Pavement Structures. Part 2. Chapter 5. Evaluation of existing pavements for rehabilitation. AASHTO; 2004.

[2] D.M. Burmister, The general theory of stresses and displacements in layered soil systems, J. Appl. Phys. 16 (1945). 2, 89-96; 3, 126-127; 4, 296-302.

[3] R.L. Lytton, Back calculation of pavement Layer Properties Nondestructive Testing of Pavements and Back calculation of Moduli, in: A.J. Bush, G.Y. Baladi (Eds.), ASTM STP 1026, ASTM, Philadelphia, 1989, pp. 7-38.

[4] E.B. Roberts, Entrepreneurs in High Technology: Lessons from MIT and Beyond, Oxford University Press, 1991. ISBN-978-0195067040.

[5] J.V. Rosetta, Feasibility Study of the Measurement of Bridge Deck Bituminous Overlay Thickness by Pulse Radar, Geophysical Survey Systems, Inc., Hudson, New Hampshire, 1980.

[6] J.R. Moore, J.D. Echard, C.G. Neill, Radar Detection of Voids under Concrete Highways," New York, The Institute of Electrical and Electronic Engineers, 1980.

[7] G.G. Clemena, K.H. McGhee, C.G. Neill, Application of Radar Subsurface Profiling in Estimating Sidewalk Undermining, Transportation Research Board, Washington DC, 1980.

[8] W.J. Steinway, J.D. Echard, C.M. Luke, Locating Voids beneath Pavement Using Pulsed Electromagnetic Waves, NCHRP Report No. 237, Transportation Research Board, Washington DC, 1981. 
[9] American Society for Testing and Materials. Standard Test Method for Determining the Thickness of Bound Pavement Layers Using Short-Pulse Radar ASTM Standard D 4748 - 87; 1987.

[10] American Society for Testing and Materials. Standard Test Method for Determining the Thickness of Bound Pavement Layers Using Short-Pulse Radar ASTM Standard D 4748 - 98; 1998.

[11] American Society for Testing and Materials. Standard Test Method for Determining the Thickness of Bound Pavement Layers Using Short-Pulse Radar ASTM Standard D 4748 - 10; 2010.

[12] S.S. Smith, T. Scullion, Development of Ground-Penetrating Radar Equipment for Detecting Pavement Condition for Preventive Maintenance, National Research Council, Washington, DC, 1993.

[13] R.A. Eckrose, Ground Penetrating Radar Supplements Deflection Testing to Improve Airport Pavement Evaluations. Non-destructive Testing of Pavements and Back Calculation of Moduli. ASTM STP 1026. ISSN 0066-0558. 1989.

[14] R.C. Briggs, T. Scullion, K.R. Maser, Asphalt thickness variation on Texas SHRP sections and effect on backcalculated moduli, in: Proceedings of the Symposium on NDT and Backcalculation, Nashville, Tennesse, 1991.

[15] K.R. Maser, Condition assessment of transportation infrastructure using ground-penetrating radar, J. Infrastruct. Syst. 2 (2) (1996). ISSN: 1076-0342. 1996.

[16] T. Saarenketo, Using ground-penetrating radar and dielectric probe measurements in pavement density quality control, Transp. Res. Rec. 1575 (1997) 34-41. ISSN: 0361-1981.

[17] I.L. Al-Qadi, O.A. Hazim, W. Su, S.M. Riad, Dielectric properties of Portland cement concrete at low radio frequencies, J. Mater. Civ. Eng. 7 (3) (1995) 192198.

[18] R.M. Morey, National cooperative highway research program synthesis 255: guide ground penetrating radar for evaluating subsurface conditions for transportation facilities, Transp. Res. Rec. (1998). ISSN-0547-5570.

[19] T. Saarenketo, T. Scullion, Road evaluation with ground penetrating radar, J. Appl. Geophys. 43 (2-4) (2000) 119-138.

[20] American Association of State Highway and Transportation Officials, Standard recommended practice for application of ground penetrating radar (GPR) to highways R 37-04, AASHTO, Washington DC, 2004.

[21] K. Maser, J. Puccinelli, J.K. Amestoy, Accuracy of ground penetrating radar asphalt thickness data and its impact on pavement rehabilitation design, Transp. Res. Rec. (2012). Monograph 12-1777.

[22] P. Shangguan, I.L. Al-Qadi, Z. Leng, R.L. Schmitt, A. Faheem, Innovative approach for asphalt pavement compaction monitoring with groundpenetrating radar, Transp. Res. Rec. 2347 (2013) 79-87.

[23] M. Celaya, F.S. Ertem, S. Nazarian, M. Saltan, Feasibility of detecting debonding of hot mix asphalt layer with nondestructive testing, in: Nondestructive Testing of Materials and Structures, pp. 877-881, ISBN: 978-94-007-0722-1. RILEM, 2013.

[24] E. Kassem, L. Walubita, T. Scullion, E. Masad, A. Wimsatt, Evaluation of fulldepth asphalt pavement construction using X-ray computed tomography and ground penetrating radar, J. Perform. Constr. Facil. 22 (2008) 408-416.

[25] L.F. Walubita, T. Scullion, J. Leidy, L. Wenting, Non-destructive technologies: application of the ground penetrating radar (GPR) to perpetual pavements, Int. J. Road Mater. Pavement Des. 10 (2) (2009) 259-286.

[26] Z. Leng, Prediction of in-situ asphalt mixture density using ground penetrating radar: theoretical development and field verification. Ph.D. Dissertation, University of Illinois at Urbana-Champaign; 2011.
[27] E.O. Brigham, The Fast Fourier Transform, Prentice-Hall Inc, Englewood Cliffs, New Jersey, 1998. ISBN: 012307496X.

[28] B.W. Carroll, D.A. Ostlie, An Introduction to Modern Astrophysics, Pearson Education, CA, USA, 2007. ISBN 0-8053-0402-9.

[29] D.J. Daniels, Ground Penetrating Radar, The Institution of Electrical Engineers, Herts, UK, 2004. ISBN: 978-0-86341-360-5.

[30] S.G. Millard, J.H. Bungey, A. Shaari, GPR Antenna medium coupling effects: experimental and 2DFDTD modelling results. Non-Destructive Testing in Civil Engineering, BAM. International Symposium, 2003.

[31] A. Benedetto, S. Pensa, Indirect diagnosis of pavement structural damages using surface GPR reflection techniques, J. Appl. Geophys. 62 (2) (2007) 107123.

[32] S. Laurens, J.P. Balayssac, J. Rhazy, G. Klysz, G. Arliguie, Non destructive evaluation of concrete moisture by GPR technique: experimental study and direct modeling. Non-Destructive Testing in Civil Engineering, BAM. International Symposium, 2003.

[33] W.L. Lai, T. Kind, H. Wiggenhauser, A Study of concrete hydration and dielectric relaxation mechanism using ground penetrating radar and shorttime Fourier transform, EURASIP J. Adv. Signal Process. 2010 (2010) 14. Article ID 317216.

[34] M.R. Clark, R. Gillespie, T. Kemp, D.M. McCann, M.C. Forde, Electromagnetic properties of railway ballast, NDT\&E Int. 34 (2001) 305-311.

[35] M. Silvast, M. Levomäki, A. Nurmikolu, J. Noukka, NDT Techniques in Railway Structure Analysis, 7th World Congress of Rail Research International Union of Railways, Montréal, Canada, 2006.

[36] W.L. Lai, T. Kind, H. Wiggenhauser, Using ground penetrating radar and timefrequency analysis to characterize construction materials, NDT\&E Int. 44 (1) (2011) $111-120$.

[37] F. Benedetto, F. Tosti, GPR spectral analysis for clay content evaluation by the frequency shift method, J. Appl. Geophys. 97 (2013) 89-96.

[38] E. Forte, M. Pipan, D. Casabianca, R. Di Cuia, A. Riva, Imaging and characterization of a carbonate hydrocarbon reservoir analogue using GPR attributes, J. Appl. Geophys. 81 (2013) 76-87.

[39] A. Benedetto, Water content evaluation in unsaturated soil using GPR signal analysis in the frequency domain, J. Appl. Geophys. 71 (1) (2010) 26-35.

[40] Asphalt Institute, Asphalt overlays for highway and street rehabilitation, Lexington, KY, USA, 2000.

[41] American Association of State Highway and Transportation Officials, Guide for Design of Pavement Structures, AASHTO, Washington DC, 1993.

[42] American Society for Testing and Materials, Standard Practice for Sampling Bituminous Paving Mixtures, ASTM Standard D, Washington DC, 2001. 979 01.

[43] W.L. Russell, Pavement Design Guide, Texas Department of Transportation, 2011.

[44] Dirección General de Carreteras del Ministerio de Fomento. Pliego de Prescripciones Técnicas Generales para Obras de Carreteras y Puentes (PG3). Actualizado por la Orden Ministerial FOM 891, 2004.

[45] E. Drumm, J. Reeves, M. Madgett, W. Trolinger, Subgrade resilient modulus correction for saturation effects, J. Geotech. Geoenviron. Eng. 123 (7) (1997) 663-670.

[46] S.M. Gomba, J. Liddle, Y.A. Mehta, Evaluation of interlayer bonding in hot mix asphalt pavements, Int. J Pavement 4 (1-2) (2005) 13-24. University of Mississippi, University, ISSN: 1676-2797. 